\title{
Effects of different light quality and biofertilizers on structural and physiological traits of spinach plants
}

\author{
L. VITALE ${ }^{*,+},+$, E. VITALE ${ }^{* *, \dagger}$, G. GUERCIA**, M. TURANO ${ }^{* *}$, and C. ARENA** \\ National Research Council (CNR), Institute for Agricultural and Forestry Systems in the Mediterranean (ISAFoM), \\ Via Patacca 85-80056, Ercolano (Na), Italy* \\ University of Naples Federico II, Department of Biology, Via Cinthia, 80126 Naples, Italy**
}

\begin{abstract}
In this work, the effects of light quality and beneficial microbes (biofertilizer) supply on structural and ecophysiological traits of spinach were investigated. Plants were grown under four light quality regimens: white light (WL), red-blue (RB), red-green $(\mathrm{RG})$, and red $(\mathrm{R})$ light, with or without the addition of biofertilizer. RG and R plants without biofertilizer showed morphological traits typical of shaded plants as wide leaf lamina and high photosynthetic pigment content. These plants also exhibited a higher photosynthetic capacity compared to WL and RB plants. The improved photosynthesis in RG plants was due to both morphological and physiological adjustments allowing a better utilisation of light energy, whereas in $\mathrm{R}$ plants it has been attributed to a reduced photorespiration rate. Biofertilizer application under WL improved plant performance enhancing photosynthesis. The high carbon gain compensates the costs of symbiosis. Biofertilizer application under R light favouring too much the microbial root colonisation, removed the benefits of symbiosis. The interaction of light quality and biofertilization significantly affects the root-microbe relationship.
\end{abstract}

Additional key words: antioxidants; gas exchange; light manipulation; photochemistry; plant-microbe interaction.

\section{Introduction}

Agroecosystems require high-energy inputs to reach a high level of productivity, deeply affecting climate and environment (Clark and Tilman 2017). For this reason, it is crucial to shift towards a sustainable agriculture to preserve natural resources and reduce the impact on the environment. Indoor cultivation by sustainable innovative tools might represent a promising solution to reduce the deleterious effects of extensive crop production on the ecosystems.

Light manipulation, through light-emitting diode (LED) technology, is becoming one of the most valuable approaches in controlled-environment agriculture. The LED technology offers many advantages over traditional forms of lighting including high luminous efficiency, reduced energy consumption and cost, and low heat production (Singh et al. 2015, Izzo et al. 2019, Paradiso et al. 2019). Moreover, the LED light systems allow managing the light spectrum composition defining specific light regimes useful for plant growth and development.

Light spectrum composition affects plant growth influencing plant anatomy, morphology, and physiology
(Ye et al. 2017, Zheng and Van Labeke 2017). In particular, red and blue wavelengths are efficiently used by photosynthetic apparatus and are fundamental for the plant healthy growth. Red light determines changes in shoot/stem ratio or shoot/root ratio, plant structure, and photosynthesis (Schuerger et al. 1997, Amitrano et al. 2018). Blue light is essential for chlorophyll biosynthesis, stomatal opening, chloroplast development and maturation, as well as synthesis of photosynthetic enzymes (Heo et al. 2002, Urbonaviciute et al. 2007, Hernández and Kubota 2016, Wang et al. 2016). The addition of green light can further increase plant biomass under certain circumstances (Kim et al. 2004, Johkan et al. 2012). Some studies have demonstrated that also green light has an essential role in controlling plant development and photosynthesis, because it penetrates deeper into the leaf mesophyll and canopy layers, driving photosynthesis where other wavelengths (i.e., red and blue) are limiting (Terashima et al. 2009, Folta 2005, Smith et al. 2017). Green light has been rarely mixed to red and blue wavelengths for leafy vegetable production (Arena et al. 2016, Hristozkova et al. 2017). For this reason, further investigations are needed to assess if the beneficial effects of green light are the result of a

\footnotetext{
Received 28 February 2020, accepted 29 April 2020.

${ }^{+}$Corresponding author; phone: +390817886701 , fax: +390817718045 , e-mail: luca.vitale@enr.it

Abbreviations: Anth - anthocyanin; Car - carotenoid; $C_{\mathrm{c}}$ - chloroplast $\mathrm{CO}_{2}$ concentration; DAS - days after sowing; ETR - electron transport rate; ETR $/ P_{\operatorname{gmax}}$ - electron sink processes other than carbon assimilation; FRAP - ferric reducing antioxidant power; $g_{\mathrm{m}}-$ mesophyll conductance; $g_{\mathrm{s}}$ - stomatal conductance; I - inoculated; LDMC - leaf dry mass content; LMA - leaf mass per area; LT - leaf thickness; NI - noninoculated; $P_{\mathrm{g} \max }-$ light-saturated gross photosynthetic rate; $P_{\mathrm{Nmax}}-$ light-saturated net photosynthetic rate; TP - total polyphenols; TSC - total soluble carbohydrates; $\Phi_{\mathrm{NO}}$ - quantum yield of nonregulated energy dissipation; $\Phi_{\mathrm{NPQ}}-$ quantum yield of regulated energy dissipation; $\Phi_{\mathrm{PSII}}$ - effective quantum yield of PSII photochemistry.

†Co-first author.
} 
direct effect on photosynthesis or rather is responsible for other light-mediated morphogenic mechanisms.

Light quality may also enhance the production of bioactive compounds, improving the nutraceutical properties of some crop species. More specifically, the selection of specific wavelengths influences the biosynthesis of polyphenols (e.g., phenols, flavonoids, anthocyanins, etc.) (Victório et al. 2015, Ye et al. 2017) and other antioxidant compounds (e.g., ascorbic acid, tocopherols, carotenoids, etc.) (Samuoliene et al. 2016) with valuable effects on human health.

Besides light quality, the addition of beneficial microorganisms to soil is a conventional practice to improve plant productivity as it influences the availability and the uptake of macro and micronutrients (Ahemad and Kibret 2014, Nascente et al. 2017) or the synthesis of natural growth regulators (i.e., hormones) (Spaepen and Vanderleyden 2011). Furthermore, microorganisms offer to plant the protection from pathogens through antimicrobials production, trigger the accumulation and/or release of secondary metabolites, and stimulate the induction of systemic resistance (Compant et al. 2005, Mhlongo et al. 2018). All these aspects contribute to the overall plant health status and represent an attractive alternative to the use of synthetic chemicals for sustainable agriculture with benefits on both human health and the environment.

It is noteworthy that light extent and quality directly or indirectly influence microbial growth. Bacteria and fungi perceive the environmental light conditions through light-sensing proteins and modulate their growth in response to light (Purschwitz et al. 2007, Hristozkova et al. 2017). Some studies show that blue wavelengths inhibit bacteria and fungi growth (De Lucca et al. 2012) whereas red wavelengths promote the formation of arbuscular mycorrhizal fungi (AMF) (Cruz 2016). Light may also indirectly affect microbial growth as it stimulates the production of photosynthetic exudates that represent a source of readily available nutrients for microorganisms (Doornbos et al. 2012). Thus, any influence of light on plant metabolism or microorganism growth may influence plant-microorganism interactions. These relationships are species-specific for plants and microorganisms and might depend on the applied light quality regimen (Hristozkova et al. 2017). Current knowledge on the combined effects of light quality and beneficial microorganisms on plant growth is limited (Alsanius et al. 2019); more research on this topic might help to maximise the plant productivity for food provisioning by setting-up specific growth protocols.

Among crops widely utilised in human nutrition, spinach (Spinacia oleracea L.) responds to different light quality regimens with changes in plant development and nutritional properties (Matsuda et al. 2007, 2008; Ohashi-Kaneko et al. 2007, Agarwal et al. 2018). This leaf vegetable is also sensitive to the beneficial microorganism biofertilisation as increases edible biomass, bioactive compound content, and resistance to stress (Çakmakçı et al. 2007, Zuccarini and Savé 2016, Khalid et al. 2017).

In this paper, we assessed the relationship between different light quality regimes and the application of beneficial microorganism in spinach plants. In particular, we analysed plant growth, photosynthetic behaviour, functional leaf traits and bioactive compound production under different light quality treatments, with or without the addition of plant growth-promoting microorganisms (PGPM) on the soil. The information acquired from this study will contribute to the knowledge on the light-plantmicrobe interaction and can be used to develop sustainable growth protocols for leafy crops by maximising the indoor cultivation.

\section{Materials and methods}

Plant material and experimental set-up: Seeds of spinach plants (Spinacia oleracea L.) were sown in 0.5-L plastic pots filled with a mixture of sterilised sandy soil and perlite substrate $(3: 1, \mathrm{v} / \mathrm{v})$ and placed inside a growth chamber, equipped with a LED lighting system, under four different light regimes: broad-spectrum white light (WL), red-blue (RB, emission peaks at 620 and $660 \mathrm{~nm}$, emission peak at $460 \mathrm{~nm}, 60: 40)$, red-green (RG, emission peaks at 620 and $660 \mathrm{~nm}$, emission peaks at 500 and $530 \mathrm{~nm}$, 60:40), and 'pure' red ( $\mathrm{R}$, emission peaks at 620 and $660 \mathrm{~nm}$ ) light. All plants were subjected to the same growth conditions: PPFD of $350 \mu \mathrm{mol}$ (photon) $\mathrm{m}^{-2} \mathrm{~s}^{-1}$ at the top of the canopy, $25 / 15^{\circ} \mathrm{C}$ day/night temperature, $50 / 70 \%$ day/night relative humidity, and photoperiod of $12 \mathrm{~h}$. Temperature and humidity were monitored by a digital thermo-hygrometer (HC520 Digital Thermo-Hygrometer, Cheerman, Guangdong, China), and the irradiance was measured by the Li-Cor190R quantum sensor ( $\mathrm{Li}$-Cor, Lincoln, Nebraska, USA). Plants were watered to field capacity to reintegrate water lost by evapotranspiration and fertilised every week with a complete nutritive solution composed by micronutrients, nitrogen, phosphorus, and potassium $\left(\mathrm{N}: \mathrm{P}_{2} \mathrm{O}_{5}: \mathrm{K}_{2} \mathrm{O}, 20: 20: 20 \mathrm{~g} \mathrm{~L}^{-1}\right.$ ) (Poly-Feed $G G$, Haifa Italia, Bologna). A commercial biofertilizer (RadiNET, Micosat F®, C.C.S. Aosta s.r.l., Aosta, Italy) containing mainly arbuscular mycorrhizal fungi (AMF) (Glomus genus, Rhizophagus irregularis), saprophytic fungi (Pochonia chlamydosporia, Tricoderma genus), and a reduced amount of rhizosphere bacteria (Bacillus and Streptomyces genus) was applied to soil at sowing and every week for three weeks. In each application, $0.6 \mathrm{~g}$ of biofertilizer was dissolved in $10 \mathrm{ml}$ of deionized water. For each light regime (WL, RB, RG, R), five plants were treated with biofertilizer (inoculated plants - I) and five plants without (noninoculated plants - NI); ten plants for each light regime in total.

Biometrical measurements and functional leaf trait determinations: Green leaf area per plant was measured every $20 \mathrm{~d}$, acquiring the images by a digital camera and measuring leaf expansion by Image $J$ software (Wayne Rasband NIH, http://imagej.nih.gov/ij/index.html).

Plant biomass was determined at $100 \mathrm{~d}$ after sowing (DAS) drying roots and shoots in a forced-air oven at $75^{\circ} \mathrm{C}$ up to constant mass. Functional leaf traits were monitored at harvest time (100 DAS) on five noninoculated and five inoculated plants by each light growth treatment. The leaf area $-\mathrm{LA}\left[\mathrm{cm}^{2}\right]$, leaf mass per area - LMA $\left[\mathrm{g} \mathrm{cm}^{-2}\right]$, leaf 
dry mass content - LDMC $\left[\mathrm{g} \mathrm{g}^{-1}\right]$, and leaf thickness LT $[\mu \mathrm{m}]$, were determined according to Cornelissen et al. (2003).

Photosynthetic pigment content: Total chlorophylls and carotenoids were determined at 100 DAS on five different leaf samples from each light treatment according to Lichtenthaler (1987). Pigments were extracted from samples using mortar and pestle in ice-cold $\left(4^{\circ} \mathrm{C}\right) 100 \%$ acetone and centrifuged at 5,000 rpm for $5 \mathrm{~min}$ (Labofuge GL, Heraeus Sepatech, Hanau, Germany). The absorbance of supernatants was quantified by a spectrophotometer (UV-VIS Cary 100, Agilent Technologies, Santa Clara, CA, USA) at 470, 645, and $662 \mathrm{~nm}$ and pigment concentration

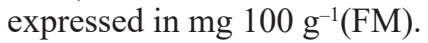

Polyphenols, anthocyanins, antioxidant capacity and carbohydrates determination were carried out on five different leaves (one leaf per plant) collected at 100 DAS. Polyphenols were determined as reported in Arena et al. (2019). Samples (0.02 g) were ground in liquid nitrogen, incubated with methanol at $4^{\circ} \mathrm{C}$, and centrifuged at 11,000 rpm for $5 \mathrm{~min}$. The supernatant was extracted and mixed with 1:1 (v/v) 10\% Folin-Ciocâlteu and 1:5 (v/v) $700 \mathrm{mM} \mathrm{Na} \mathrm{CO}_{3}$ solution. Samples were incubated at $4^{\circ} \mathrm{C}$ for $2 \mathrm{~h}$. The absorbance was quantified by a spectrophotometer (UV-VIS Cary 100, Agilent Technologies, Palo Alto, CA, USA) at $765 \mathrm{~nm}$. The total polyphenols concentration was calculated and expressed as gallic acid equivalents $\left[\mathrm{mg}(\mathrm{GAE}) 100 \mathrm{~g}^{-1}(\mathrm{FM})\right]$ using a regression equation between gallic acid standards and $\mathrm{A}_{765}$.

Total anthocyanins content was determined on $0.05-\mathrm{g}$ sample leaves ground in liquid nitrogen, treated with methanol $1 \% \mathrm{HCl}$ solution, and stored overnight at $4{ }^{\circ} \mathrm{C}$. After the addition of 1:0.6 (v/v) ultra-pure water and 1:1.6 $(\mathrm{v} / \mathrm{v})$ chloroform, samples were centrifuged at 11,000 rpm for $5 \mathrm{~min}$. Supernatant was extracted from each sample adding 1:1 (v/v) $60 \%$ methanol $1 \% \mathrm{HCl} 40 \%$ ultra-pure water solution. The absorbance was measured spectrophotometrically (UV-VIS Cary 100, Agilent Technologies, Palo Alto, CA, USA) at 530 and $657 \mathrm{~nm}$. The relative amount of anthocyanin was expressed as $\left[\left(\mathrm{A}_{530}-0.33 \mathrm{~A}_{657}\right)\right.$ $\left.100 \mathrm{~g}^{-1}(\mathrm{FM})\right]$ (Mancinelli et al. 1975).

The ferric reducing antioxidant power (FRAP) assay was performed to determine the total soluble antioxidant capacity according to method described by George et al. (2004) and modified by Motta et al. (2019). Samples (0.250 g) were ground in liquid nitrogen, treated with 60:40 (v/v) methanol/water solution and centrifuged at 14,000 rpm for $15 \mathrm{~min}\left(4^{\circ} \mathrm{C}\right)$, collecting supernatants for the assay. The FRAP reagent (1:16 $300 \mathrm{mM}$ acetate buffer $\mathrm{pH}$ 3.6; $1: 1.6$ of $10 \mathrm{mM}$ TPTZ in $40 \mathrm{mM} \mathrm{HCl} ; 1: 1.6$ of $12 \mathrm{mM}$ $\mathrm{FeCl}_{3}$ ) was added to each sample extract and the mixture incubated in the darkness for $1 \mathrm{~h}$. The sample absorbance was read by a spectrophotometer (UV-VIS Cary 100, Agilent Technologies, Palo Alto, CA, USA) at $593 \mathrm{~nm}$. Total antioxidant capacity was quantified and expressed as mmol Trolox equivalents [mmol(TE) $\left.100 \mathrm{~g}^{-1}(\mathrm{FM})\right]$ using a Trolox standard curve.

Total soluble carbohydrates content was determined on five different leaf samples $(0.01 \mathrm{~g})$ of each treatment following the anthrone method reported by Hedge and Hofreiter (1962). The absorbance was measured at $630 \mathrm{~nm}$ by a spectrophotometer (UV-VIS Cary 100, Agilent Technologies, Palo Alto, CA, USA). The amount of total soluble carbohydrates in the extracts was calculated using a glucose standard curve and expressed as glucose equivalents $\left[\mathrm{g}(\mathrm{GE}) 100 \mathrm{~g}^{-1}(\mathrm{FM})\right]$.

Photosynthetic characteristics and Chl fluorescence parameters: Gas exchange and fluorescence measurements were simultaneously performed on fully expanded leaves by means of LI-6400 ( $\mathrm{Li}$-Cor, Lincoln, Nebraska, USA) integrated with LI-6400-40 leaf chamber fluorometer. Light-response curves (LRC) were carried out illuminating the leaves with red plus blue LEDs at $25^{\circ} \mathrm{C}$, $360 \mu \mathrm{mol}\left(\mathrm{CO}_{2}\right) \mathrm{mol}^{-1}$, and $50 \%$ air relative humidity (RH) to determine the light-saturated net photosynthesis. Net photosynthetic rate $\left(P_{\mathrm{N}}\right)$, stomatal conductance $\left(g_{\mathrm{s}}\right)$, and intercellular $\mathrm{CO}_{2}$ concentration $\left(C_{\mathrm{i}}\right)$ were calculated according to von Caemmerer and Farquhar (1981). At each irradiance level, the steady-state fluorescence yield $\left(\mathrm{F}_{\mathrm{s}}\right)$ and the maximal fluorescence yield in the light-adapted state $\left(\mathrm{F}_{\mathrm{m}}{ }^{\prime}\right)$ were measured applying a $0.8 \mathrm{~s}$-saturating flash of $8,000 \mu \mathrm{mol}$ (photon) $\mathrm{m}^{-2} \mathrm{~s}^{-1}$, and the effective quantum yield of PSII photochemistry ( $\left.\Phi_{\mathrm{PSII}}\right)$ (Genty et al. 1989), the regulated $\left(\Phi_{\mathrm{NPQ}}\right)$ and the nonregulated $\left(\Phi_{\mathrm{NO}}\right)$ energy dissipation (Kramer et al. 2004) were calculated. Electron sink processes other than carbon assimilation $\left(\mathrm{ETR} / P_{\text {gmax }}\right)$ were evaluated by the ratio between the electron transport rate (ETR) and light-saturated gross photosynthetic rate $\left(P_{\text {gmax }}\right)$ (Krall and Edwards 1992). Maximal quantum yield of PSII photochemistry $\left(\mathrm{F}_{\mathrm{v}} / \mathrm{F}_{\mathrm{m}}\right)$ was measured at the end of each LRC on 30-min dark-adapted leaves measuring the minimal fluorescence of the dark-adapted state $\left(\mathrm{F}_{0}\right)$ and maximal fluorescence yield of the dark-adapted state $\left(\mathrm{F}_{\mathrm{m}}\right)$, applying a saturation pulse of $8,000 \mu \mathrm{mol}$ (photon) $\mathrm{m}^{-2} \mathrm{~s}^{-1}$. Mesophyll conductance $\left(g_{\mathrm{m}}\right)$ was determined at $360 \mu \mathrm{mol}\left(\mathrm{CO}_{2}\right) \mathrm{mol}^{-1}$ by the variable $J$ method (Loreto et al. 1992), assuming that all the reducing power generated by the electron transport chain is used for photosynthesis and photorespiration and that chlorophyll fluorescence gives a reliable estimation of the quantum yield of electron transport. Mitochondrial respiration in the light $\left(R_{\mathrm{L}}\right)$ and the $\mathrm{CO}_{2}$-compensation point in the absence of day respiration $\left(T^{*}\right)$ were estimated according to Laisk and Oja (1998) by performing $P-C_{\mathrm{i}}$ response curves at three different light intensities and using only the points on the linear portion of the curves. $g_{\mathrm{m}}$ was used to calculate the concentration of $\mathrm{CO}_{2}$ at the sites of carboxylation $\left(C_{\mathrm{c}}\right)$.

Arbuscular mycorrhizal fungi (AFM) colonization assay: A set of plants was used for AMF colonization assay in WL and R plants. Pieces of roots were cleared in $10 \% \mathrm{KOH}$ and stained with $0.05 \%$ aniline blue in vinegar 5\% (v/v), according to Vierheilig et al. (1998) and Vierheilig and Piché (1998). Images were acquired by light microscopy (Nikon Eclipse E1000, Nikon Instruments Inc., Melville, New York, USA) using a digital camera (Nikon DXM1200F Microscope Camera, Nikon Instruments Inc., 
Melville, New York, USA). The root colonization was expressed as $\%$ considering the ratio between the number of root fragments showing colonization and the total number of root fragments observed; the root infection was expressed as number of vesicles presenting on a $\mathrm{cm}$ of root fragment.

Statistical analysis was performed by Sigma-Plot 12.0 software package (Jandel Scientific, San Rafael, CA, USA). Data were analysed by two-way ANOVA followed by the Duncan's test for multiple comparison procedures. The results are reported as mean $(n=5) \pm$ standard deviation. Differences were considered statistically significant at $p \leq 0.05$. Shapiro-Wilk's and Kolmogorov-Smirnov's tests were performed to check for normality. The correlations between selected parameters were investigated using Pearson's correlation test.

\section{Results}

Root colonization by AMF: Spinach roots resulted colonized by AMF (Fig. 1). Roots of plants grown under monochromatic red light showed a higher microbe infection compared to plants grown under white light (Table 1).

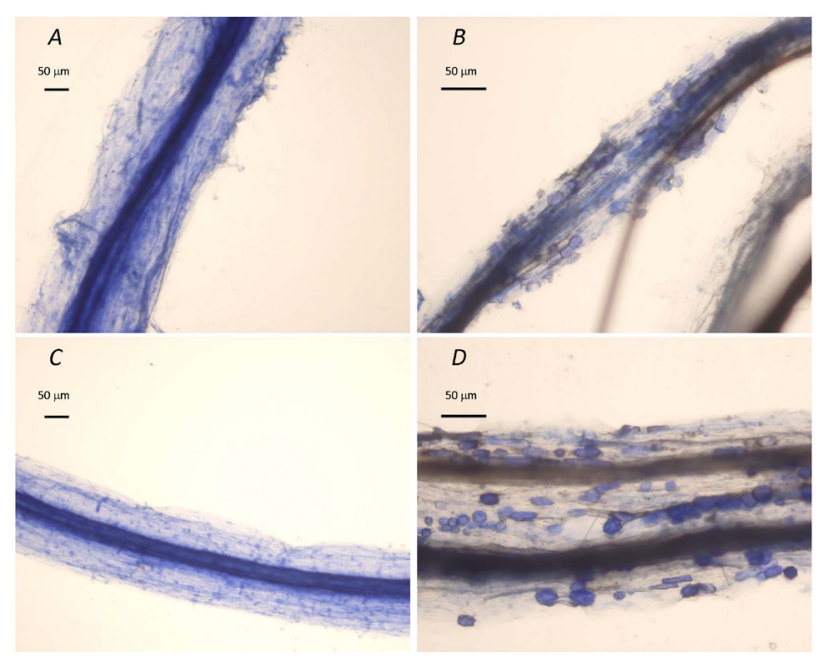

Fig. 1. Microbe infection in spinach roots. Noninoculated plants under white light, WL $(A)$; inoculated plants under WL $(B)$; noninoculated plants under pure $\mathrm{R}$ light, $\mathrm{R}(C)$; inoculated plants under pure $\mathrm{R}$ light, $\mathrm{R}(D) .10 \times$ magnification $-A, C$; $20 \times$ magnification $-B, D$. Scale bar $=50 \mu \mathrm{m}$.
Plant growth and leaf functional traits: The diverse light treatments significantly affected the plant morphology (Fig. 1S, supplement). The total biomass did not change under different light treatments compared to WL in both NI and I plants (Fig. 2A). The combination light treatments $\times$ biofertilisation produced a rise of the biomass in I compared to NI plants only under RG light treatment. Conversely to dry shoot mass (Fig. 2B), the interaction light quality $\times$ biofertilizer affected root dry mass production (Fig. 2C). Among all light treatments, RB light promoted root biomass accumulation in noninoculated plants. The addition of biofertilizer to light treatments induced a significant rise of root biomass in WL and RG plants compared to respective noninoculated samples. The shoot/root ratio was the lowest in RB noninoculated plants compared to other light treatments. The biofertilizer application under different light quality treatments did not induce an increase of the root/shoot ratio, compared to noninoculated plants, except for RB plants that show a slight significant increase (Fig. 2D). As regards leaf functional traits, plants grown under $\mathrm{RG}$ and $\mathrm{R}$ light treatments showed leaves with greater area, lower LMA and LT compared to WL and RB plants (Table 2). These latter were characterised by high values of LMA and LDMC. The interaction biofertilizer $\times$ light treatment affected only R plants (I-R) where leaves with lower LA and higher LMA were found compared to noninoculated ones.

Photosynthetic and $\mathrm{Chl}$ fluorescence parameters: Light quality influenced leaf gas exchanges in both noninoculated (NI) and inoculated (I) plants (Fig. 3). The light-saturated net photosynthetic rate $\left(P_{\mathrm{Nmax}}\right)$, stomatal $\left(g_{\mathrm{s}}\right)$ and mesophyll $\left(g_{\mathrm{m}}\right)$ conductance to $\mathrm{CO}_{2}$ were higher in $\mathrm{RB}, \mathrm{RG}$, and $\mathrm{R}$ compared to $\mathrm{WL}$ plants, reaching a maximum under pure $\mathrm{R}$ light treatments (Fig. $3 A-C$ ). In inoculated plants, the highest values were observed under RG treatment. The addition of biofertilizer significantly increased $P_{\mathrm{Nmax}}, g_{\mathrm{s}}$, and $g_{\mathrm{m}}$ in WL and RB plants, whereas significantly reduced these parameters under pure $\mathrm{R}$ treatment. The concentration of $\mathrm{CO}_{2}$ at carboxylation sites $\left(C_{\mathrm{c}}\right)$ was higher under $\mathrm{RG}$ and $\mathrm{R}$ compared to WL and $\mathrm{RB}$ light growth regimes in both NI and I plants (Fig. 3D). The noninoculated R plants showed the highest $C_{\mathrm{c}}$ value. The interaction light $\times$ biofertilizer was significant only for $\mathrm{R}$ plants showing a reduction of $C_{\mathrm{c}}$ in I compared to NI plants.

The effective quantum yield of PSII photochemistry $\left(\Phi_{\mathrm{PSII}}\right)$ increased under $\mathrm{RB}, \mathrm{R}$, and $\mathrm{RG}$ light treatment

Table 1. Root colonization [\%] and root infection [number of vesicles per $\mathrm{cm}$ ] in noninoculated (NI) and inoculated (I) plants. Data are means $\pm \mathrm{SD}(n=5)$. Results were analysed by two-way ANOVA followed by Duncan's multiple range test. Capital letters indicate significant differences between $\mathrm{WL}$ and $\mathrm{R}$ light treatments in inoculated (I) plants $(p \leq 0.05)$. Asterisks represent different levels of significance $\left({ }^{* * *} p \leq 0.001\right)$. WL - white light; $\mathrm{R}$ - pure red light; $\mathrm{L}$ - light treatment; $\mathrm{B}$ - biostimulant; $\mathrm{L} \times \mathrm{B}$ - interaction light $\times$ biostimulant.

\begin{tabular}{|c|c|c|c|c|c|c|c|}
\hline \multirow[t]{2}{*}{ Parameters } & \multicolumn{2}{|c|}{ WL } & \multicolumn{2}{|l|}{$\mathrm{R}$} & \multicolumn{3}{|c|}{$A N O V A$} \\
\hline & NI & I & NI & I & $\mathrm{L}$ & $\mathrm{B}$ & $\mathrm{L} \times \mathrm{B}$ \\
\hline Colonization [\%] & 0 & $72.00 \pm 4.80^{\mathrm{B}}$ & 0 & $94.00 \pm 7.17^{\mathrm{A}}$ & $* * *$ & $* * *$ & $* * *$ \\
\hline Infection [vesicles $\mathrm{cm}^{-1}$ ] & 0 & $33.95 \pm 5.30^{\mathrm{B}}$ & 0 & $111.27 \pm 37.93^{\mathrm{A}}$ & $* * *$ & $* * *$ & $* * *$ \\
\hline
\end{tabular}




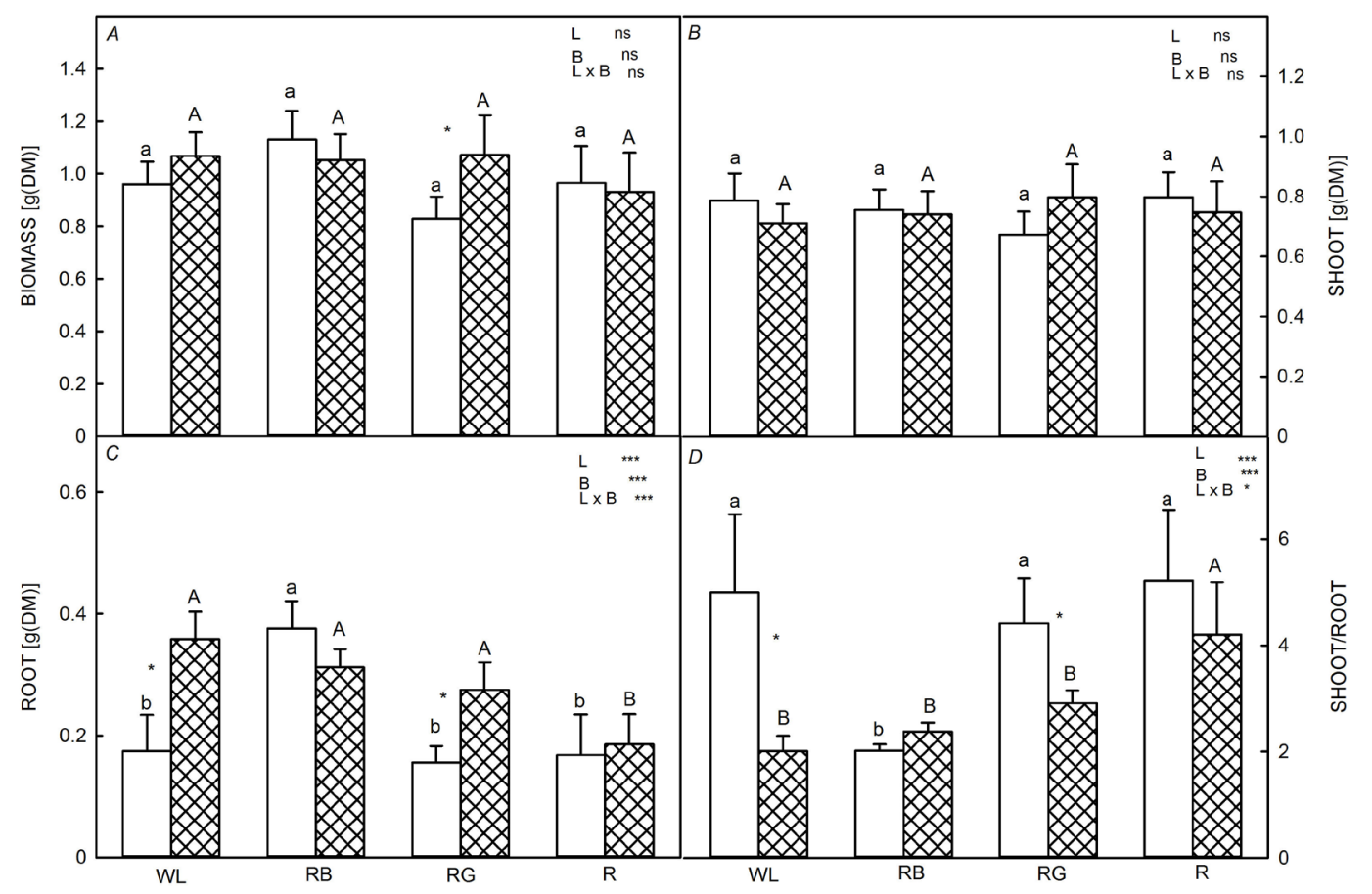

Fig. 2. Total biomass $(A)$, shoot $(B)$, and root $(C)$ biomass, and shoot/root ratio $(D)$ in noninoculated (white bar) and inoculated (full bar) plants. WL - white light; RB - red + blue light; RG - red + green light; R - pure red light. Data are means $\pm \operatorname{SD}(n=5)$. Results were analysed by two-way ANOVA followed by Duncan's multiple range test. Significant differences $(p \leq 0.05)$ were indicated by small letters between noninoculated (NI) and capital letters between inoculated (I) plants. Significant differences $(p \leq 0.05)$ between NI and I plant groups inside each light treatment are indicated with an asterisk ( $\left.{ }^{*}\right)$. The number of asterisks in ANOVA represents different levels of significance $\left({ }^{* * *} p \leq 0.001,{ }^{* *} p \leq 0.01,{ }^{*} p \leq 0.05\right)$ among light treatment (L), biostimulant (B), and the interaction light $\times$ biostimulant $(\mathrm{L} \times \mathrm{B}) ;$ ns - not significant.

compared to WL (Fig. 4A). The interaction light $\times$ biofertilizer determined a remarkable increase of $\Phi_{\text {PSII }}$ in WL plants and a significant reduction in $\mathrm{R}$ plants. The quantum yield of regulated energy dissipation $\left(\Phi_{\mathrm{NPQ}}\right)$ showed an opposite trend, inducing a decrease of $\Phi_{\mathrm{NPQ}}$ in $\mathrm{WL}$ and an increase in $\mathrm{R}$ plants (Fig. 4B). A significant increase of nonregulated energy dissipation $\left(\Phi_{\mathrm{NO}}\right)$ was observed only under $\mathrm{R}$ treatment regardless of biofertilizer application (Fig. 4C). The pure $\mathrm{R}$ treatment determined a reduction of $\mathrm{ETR} / P_{\text {gmax }}$ ratio compared to the other light regimes (Fig. 4D). An interaction light $\times$ biofertilizer was found only for $\Phi_{\text {PSII }}$. In particular, under WL the application of biofertilizer increased $\Phi_{\text {PSII }}$, while it decreased $\Phi_{\text {PSII }}$ under R light.

Bioactive compounds: Plants grown under $\mathrm{RG}$ and $\mathrm{R}$ light treatments showed a significant increase of total chlorophyll and carotenoid content, compared to WL and $\mathrm{RB}$ plants, with the highest value in $\mathrm{R}$ plants. Within $\mathrm{R}$ light treatment, the application of biofertilizer induced a reduction of photosynthetic pigment content in I compared to NI plants (Table 3 ). The total polyphenol content was significantly reduced in RB, RG, and R compared to WL plants (Table 3); the application of biofertilizer increased polyphenol content only in RG inoculated plants compared to noninoculated but did not affect the anthocyanins content that was the same for both NI and I RG plants. Conversely, the addition of biofertilizer decreased anthocyanin amount in WL and RB plants compared to noninoculated samples
(Table 3). The soluble antioxidant capacity was higher in $\mathrm{RG}$ and $\mathrm{R}$ compared to $\mathrm{WL}$ and $\mathrm{RB}$ plants in both inoculated and noninoculated plants. The total soluble carbohydrate content was lower in $\mathrm{RG}$ and $\mathrm{R}$ compared to WL and RB plants in both inoculated and noninoculated plants, with the lowest values for R plants (Table 3 ).

Correlation among the investigated leaf parameters: $P_{\text {Nmax }}$ was positively correlated to $g_{\mathrm{s}}(r=0.891)$ and $g_{\mathrm{m}}$ $(r=0.799), \Phi_{\text {PSII }}(r=0.841)$, photosynthetic pigments $(r=0.560)$, and antioxidant capacity $(r=0.635)$, and was negatively correlated to $\Phi_{\mathrm{NPQ}}(r=-0.856)$ (Table 4$)$. This latter was negatively correlated to LMA $(r=-0.610)$ and LDMC $(r=-0.653) . g_{\mathrm{m}}$ was negatively correlated to LMA $(r=-0.838)$ and LMDC $(r=-0.783)$. $\Phi_{\mathrm{PSII}}$ was negatively correlated to $\Phi_{\mathrm{NPQ}}(r=-0.826)$ and anthocyanins content $(r=-0.379)$, and positively correlated to soluble antioxidant capacity $(r=0.569)$ (Table 4$)$. This latter was positively correlated to photosynthetic pigment content $(r=0.544)$ and negatively correlated to total polyphenol amount $(r=-0.403)$ and $\Phi_{\mathrm{NPQ}}(r=-0.759)$ (Table 4).

\section{Discussion}

Plant growth, photosynthesis, and bioactive compound production: The manipulation of the light spectrum allows to obtain specific physiological responses in spinach plants associated with the modulation of photosynthesis and the synthesis of bioactive compound. Our data indicate that 


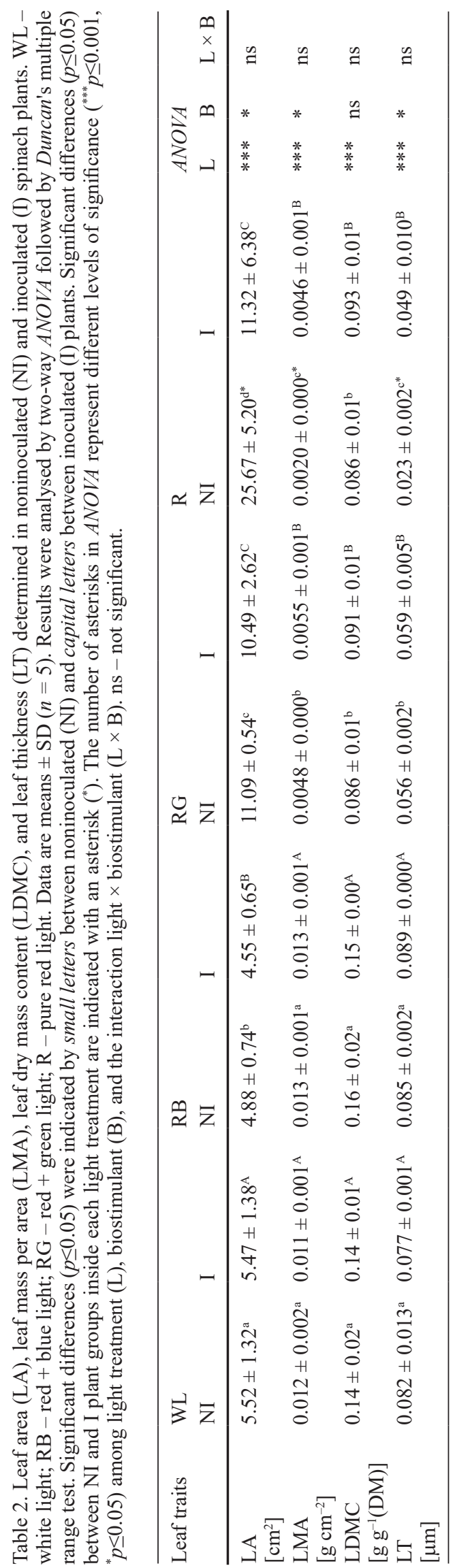

the RB light treatment, without biofertilisation, induced a partitioning of biomass toward roots compared to the other light regimes, confirming the positive influence of blue light on root development (Canamero et al. 2006) and the requirement of blue light for the optimal growth of spinach plants (Yorio et al. 2001, Agarwal et al. 2018). Generally, the absence of blue light or its insufficient or excessive amount, determined shade-avoidance responses, causing a reduction of total biomass and an imbalance in plant development (Chang et al. 2016, Yorio et al. 2001, Hernández and Kubota 2016, Agarwal et al. 2018). In our experiment, plants grown without blue light (RG and $\mathrm{R}$ plants) developed typical traits of a shade-avoidance syndrome (i.e., higher leaf area and elongated shoots and petioles) but did not reduce their biomass. These plants showed morphological, physiological, and biochemical adjustments favouring the carbon gain. Beside a greater leaf area per plant, the changes included thinner leaves characterised by lower LMA and LDMC values and high chlorophylls and carotenoid content compared to the other light treatments. These specific traits may be associated with a more efficient light harvesting and $\mathrm{CO}_{2}$ distribution inside the leaf and may have favoured the photosynthesis.

Leaf structure is an important determinant in controlling photosynthesis because it influences the light distribution within leaf as well as the $\mathrm{CO}_{2}$ diffusion at the carboxylation sites. The light wavelengths are selectively absorbed and distributed inside the leaf. Red or blue light is largely absorbed by chloroplasts near leaf surface, whereas green penetrating deeper than red or blue light, drives the photosynthesis deeply in the mesophyll (Terashima et al. 2009). We hypothesise that the development of thin leaves under $\mathrm{RG}$ and $\mathrm{R}$ light treatments allowed light to penetrate deeper in the leaf layers. The reduced content of anthocyanins and polyphenols in plants grown under green wavelengths also may be associated with a more light penetration within leaf tissues since these compounds act as a natural filter against the light (Steyn et al. 2002, Landi et al. 2015). The reduced LMA and LDMC in RG and much more in $\mathrm{R}$ leaves contributed to alleviation of the limitations to the $\mathrm{CO}_{2}$ diffusion in the mesophyll (Niinemets et al. 2009). We assumed that the higher photosynthetic rate of $\mathrm{RG}$ and $\mathrm{R}$ plants was due to the higher stomatal and mesophyll conductance. In fact, the reduced leaf thickness and tissue density shortening the pathway of $\mathrm{CO}_{2}$ diffusion toward chloroplasts, likely helped gas exchange. The plant growth under green light (RG) developed leaves with higher $\Phi_{\mathrm{PSII}}$ and carbohydrate content compared to pure $\mathrm{R}$ leaves, indicating that the green wavelength drives a higher utilisation of radiant energy in photochemistry. The improved $\mathrm{CO}_{2}$ diffusion in $\mathrm{R}$ compared to $\mathrm{RG}$ leaves was the main reason for the stimulation of photosynthesis in these plants. Such elevated $\mathrm{CO}_{2}$ concentration in the chloroplasts significantly reduced the photorespiration, according to $\Phi_{\mathrm{PSII}}$ decline and $\mathrm{ETR} / P_{\text {gmax }}$ ratio value near to the theoretical threshold of 4-5. The decrease of photorespiration determined the rise of $\Phi_{\mathrm{NO}}$ and the decline of $\Phi_{\mathrm{NPQ}}$, exposing plants to the risks of reactive oxygen species (ROS) accumulation (Agarwal et al. 2018), this could be a reason by which in 


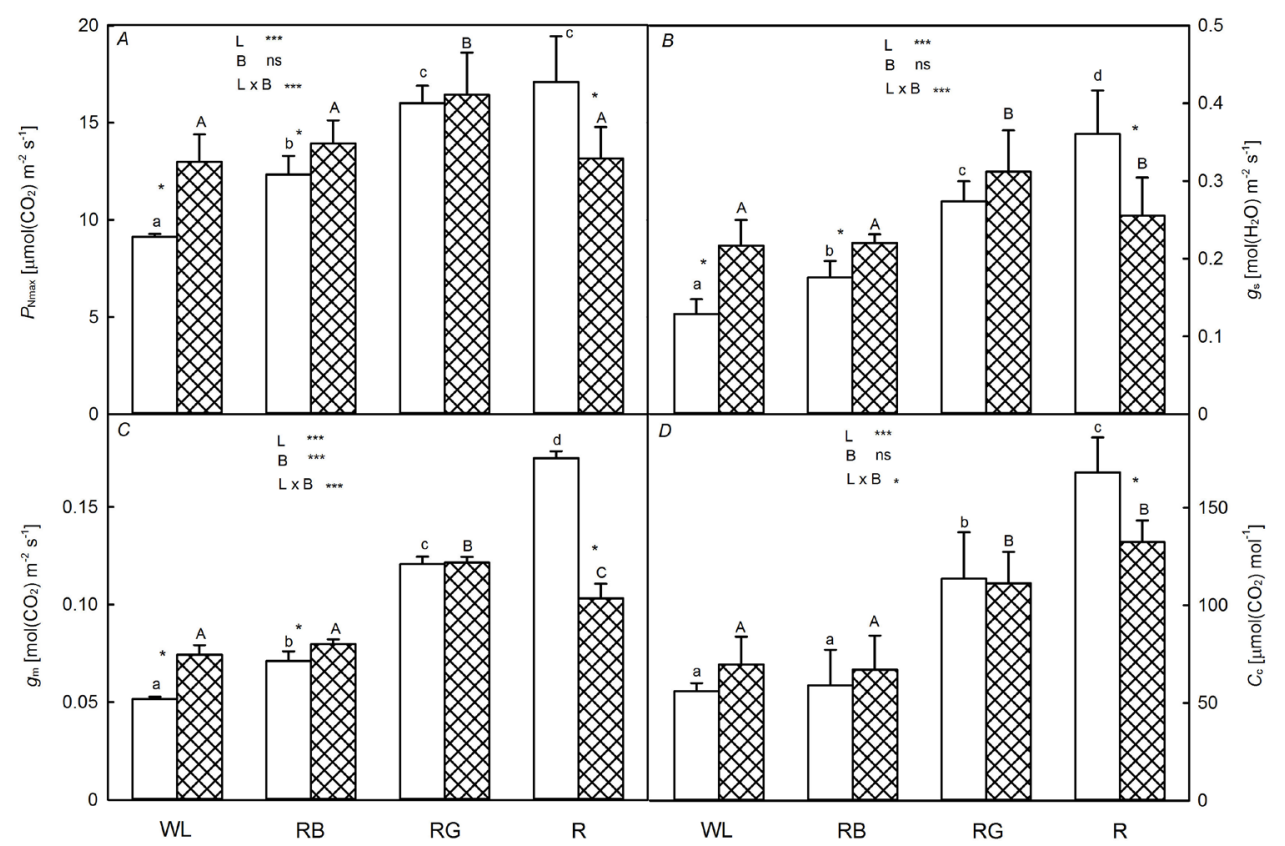

Fig. 3. Light-saturated net photosynthetic rate $\left(P_{\mathrm{Nmax}}\right)(A)$, stomatal conductance $\left(g_{\mathrm{s}}\right)(B)$, mesophyll conductance $\left(g_{\mathrm{m}}\right)(C)$, chloroplast $\mathrm{CO}_{2}$ concentration $\left(C_{\mathrm{c}}\right)(D)$ in noninoculated (white bar) and inoculated (full bar) plants. WL - white light; RB - red + blue light; RG red + green light; $\mathrm{R}$ - pure red light. Data are means $\pm \mathrm{SD}(n=5)$. Results were analysed by two-way ANOVA followed by Duncan's multiple range test. Significant differences $(p \leq 0.05)$ were indicated by small letters between noninoculated (NI) and capital letters between inoculated (I) plants. Significant differences $(p \leq 0.05)$ between NI and I plant groups inside each light treatment are indicated with an asterisk $\left({ }^{*}\right)$. The number of asterisks in ANOVA represents different levels of significance $\left({ }^{* * *} p \leq 0.001,{ }^{* *} p \leq 0.01,{ }^{*} p \leq 0.05\right)$ among light treatment (L), biostimulant $(\mathrm{B})$, and the interaction light $\times$ biostimulant $(\mathrm{L} \times \mathrm{B})$; ns - not significant.

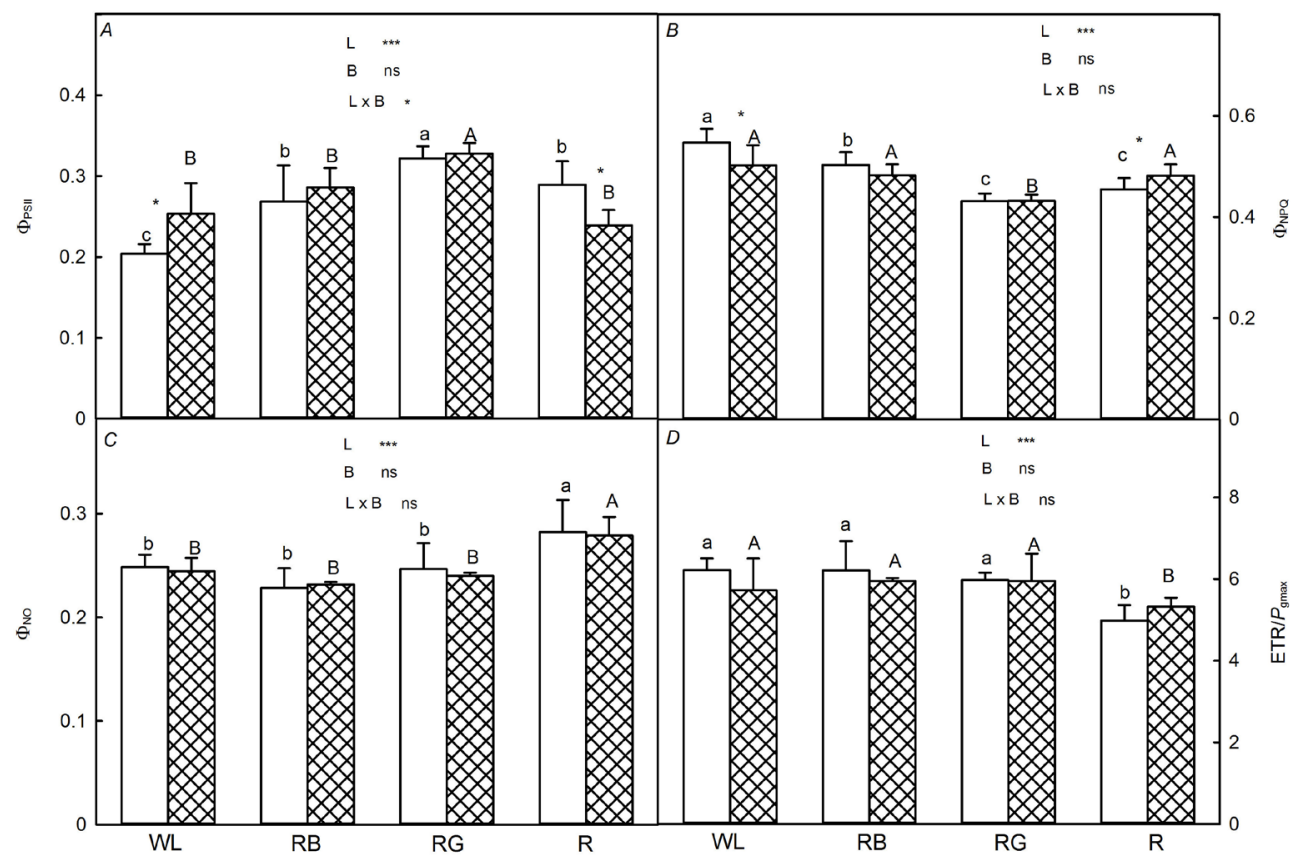

Fig. 4. Effective quantum yield of PSII photochemistry $\left(\Phi_{\mathrm{PSII}}\right)(A)$, quantum yield of regulated energy dissipation $\left(\Phi_{\mathrm{NPQ}}\right)(B), \mathrm{quantum}$ yield of nonregulated energy dissipation $\left(\Phi_{\mathrm{No}}\right)(C)$, electron sink processes other than carbon assimilation $\left(\mathrm{ETR} / P_{\mathrm{gmax}}\right)(D)$ in noninoculated (white bar) and inoculated (full bar) plants. WL - white light; RB - red + blue light; RG - red + green light; $\mathrm{R}-$ pure red light. Data are means $\pm \mathrm{SD}(n=5)$. Results were analysed by two-way ANOVA followed by Duncan's multiple range test. Significant differences $(p \leq 0.05)$ were indicated by small letters between noninoculated (NI) and capital letters between inoculated (I) plants. Significant differences $(p \leq 0.05)$ between NI and I plant groups inside each light treatment are indicated with an asterisk $\left({ }^{*}\right)$. The number of asterisks in ANOVA represents different levels of significance $\left({ }^{* * *} p \leq 0.001,{ }^{* *} p \leq 0.01,{ }^{*} p \leq 0.05\right)$ among light treatment (L), biostimulant (B), and the interaction light $\times$ biostimulant $(\mathrm{L} \times \mathrm{B})$; ns - not significant. 


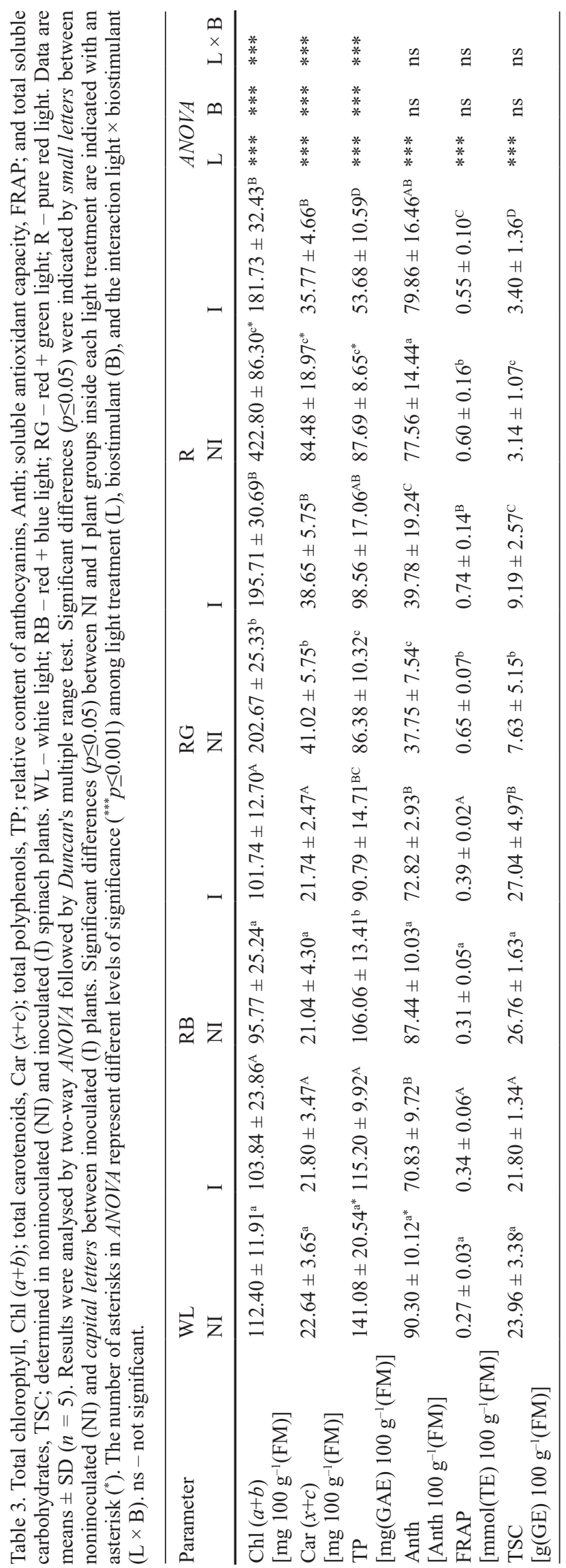

RG and $\mathrm{R}$ plants increased significantly the antioxidant capacity in order to counteract efficiently the oxidative stress. Changes in the light spectrum are also responsible for changes in the amounts of polyphenols. The absence of blue wavelengths in $R G$ and $R$ treatments led to a drastic reduction of polyphenols content in spinach plants, emphasising the critical role exerted by blue light on the synthesis of the secondary metabolites.

Compared to WL, considered as control, the growth under red-blue (RB) light improved both stomatal and mesophyll conductance, stimulating photosynthesis. This result is consistent with previous studies on tomato and oriental plane (Arena et al. 2016). Other authors reported no benefits of blue light on photosynthesis in spinach (Yorio et al. 2001, Agarwal et al. 2018) or a reduced photosynthesis and mesophyll conductance in other species (Loreto et al. 2009, Pallozzi et al. 2013). As no difference was found between WL and RB in leaf functional traits affecting $g_{\mathrm{m}}$ (i.e., LT, LMA, and LDMC) (Tomás et al. 2013), we supposed that other factors were responsible for the high photosynthetic performance of RB compared to WL plants.

The high $\Phi_{\text {PSII }}$ in RB plants may indicate an enrichment of electron transport, likely mediated by an enhancement of cytochrome $f$ (Cyt $f$ ) complex. Matsuda et al. (2007) reported an increase in Cyt $f$ content in spinach plants grown under a blue light intensity of $300 \mu \mathrm{mol}($ photon) $\mathrm{m}^{-2} \mathrm{~s}^{-1}$, similar to that utilised in our study. From biochemical point of view, the plant growth under $\mathrm{RB}$ light induced a reduction of polyphenols content compared to WL. This result was in contrast with previous studies on spinach plants (Agarwal et al. 2018) and other crops (Tomás et al. 2013).

Generally, polyphenols contribute to the second antioxidant system and are engaged when primary antioxidants are exhausted, such as under stress circumstances. Their synthesis, driven by blue light, is mediated by cytochrome $\mathrm{P}_{450}$ and lead to ROS accumulation (Lobiuc et al. 2017). Based on this statement, we supposed no stress condition for spinach plants at blue light intensity utilised in our study. Also, the content of anthocyanins and total antioxidant capacity in RB plants comparable to WL control seems to suggest the absence of stress due to prolonged growth under blue light.

Light quality and plant-microorganism interaction: Beneficial microorganisms (PGPM) such as fungi and bacteria added to plant growth mean may improve productivity and tissue nutraceutical value eventually potentiating the effect of specific light wavelengths. At present, little information is available on the interplay between light quality and beneficial microbes on plant physiological performance. Our data demonstrated that arbuscular mycorrhizal fungi (AMF) infected the spinach roots. The results are in agreement with other studies demonstrating that AMF belonging to Glomus genus infect spinach roots (Zuccarini and Savé 2016, Khalid et al. 2017) and the higher root infection occurred with rhizobacterial inoculation (Khalid et al. 2017). The inoculation of spinach plant under white light regime 


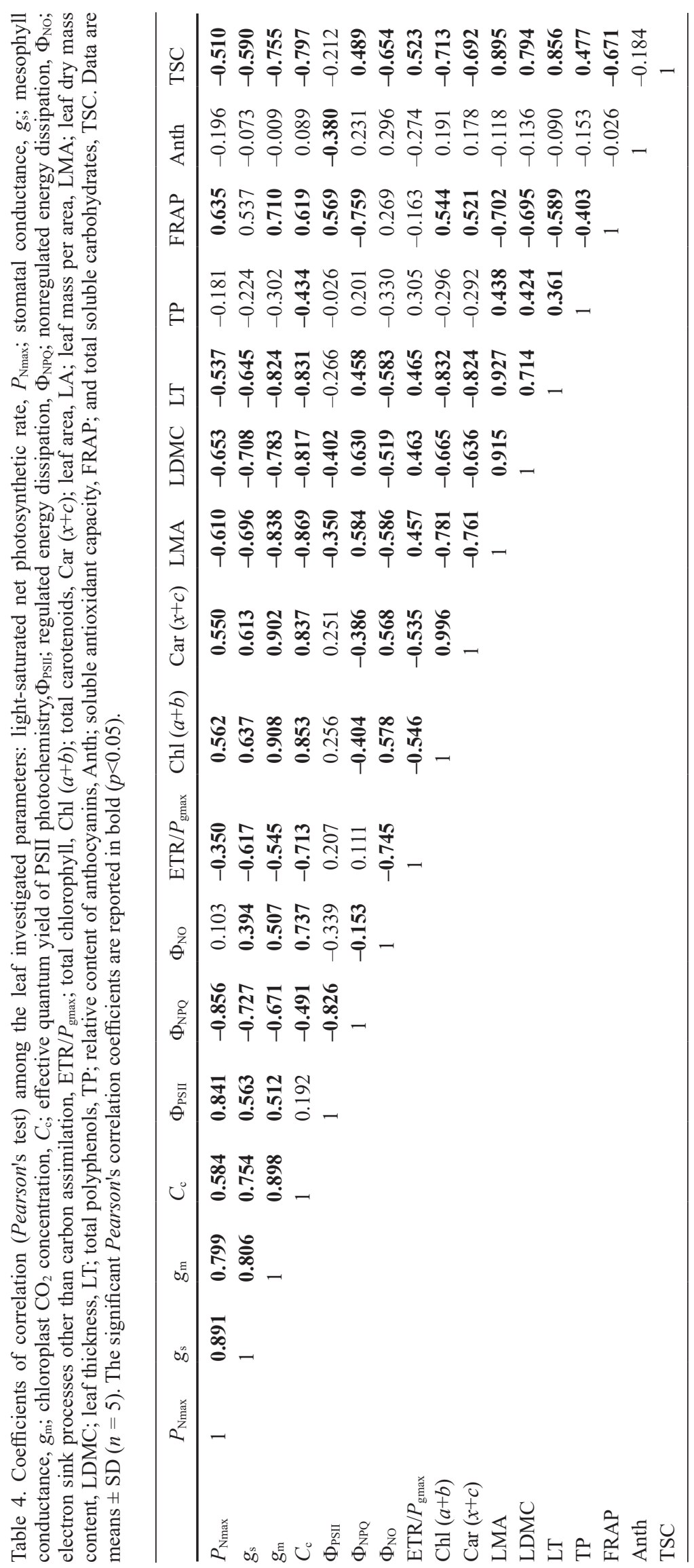


promoted the growth enhancing the dry mass production mainly in the roots. The PGPM addition improved nutrient uptake, phosphorus solubility, and hormones production, while host plant sustained symbiotic costs by supplying photosynthates for microbe metabolism and growth. In WL inoculated plants (WL-I), $P_{\text {Nmax }}$ was upregulated likely to compensate for the costs of symbiosis (Kaschuk et al. 2009). The improved $\mathrm{CO}_{2}$ uptake was attributed to the rise of both $g_{\mathrm{s}}$ and $g_{\mathrm{m}}$ as well as to an increase of ETR. The enhanced electron transport capacity may be the consequence of a high nutrient availability promoted by beneficial microorganisms (Walker et al. 2014). Consistent with studies of Khalid et al. (2017) on spinach, we found in WL inoculated plants a lower polyphenol and anthocyanin content and a high antioxidant capacity compared to noninoculated samples. In our opinion, the high antioxidant capacity might balance the low polyphenol amount, increasing the scavenging potential of the inoculated plants.

The interaction with light quality changes the relationships between plants and microorganisms. Several studies demonstrated the importance of light for the symbiotic functioning of PGPM, and in particular for AMF. Hristozkova et al. (2017) showed for the first time the influence of light quality on mycorrhizal symbiosis formation in tomato, indicating how the phenotypic plasticity was affected by light spectral composition. In our study, a different phenotypic plasticity was found in several key traits of inoculated plants confirming that different light quality regimes strongly change the plant's plastic responses to beneficial microorganisms. In our experiment, red light strongly promoted the root colonization by microbes, enhancing the development of arbuscular mycorrhizal fungi, in particular Glomus (Cruz 2016). Conversely, blue wavelengths seemed to inhibit bacteria and fungi growth (De Lucca et al. 2012). If the interaction light quality $\times$ microorganisms is favourable under WL and RB light treatments, it becomes null or negative in $\mathrm{RG}$ and $\mathrm{R}$ plants, respectively. It is likely to suppose that in inoculated $\mathrm{R}$ plants the energetic costs of the symbiosis became too elevated for the high AMF colonisation. Thus, the decrease of photosynthesis was likely due to the strong microorganisms' carbon demand. Under RG treatment, the inoculated plants were able to pay for the energy cost of symbiosis, increasing photosynthesis thanks also to beneficial properties of the green wavelength. The RG plants, investing more carbon in aboveground biomass compared to shoots, improved the nutrient uptake by the roots. The interplay of RB light and microorganisms increased photosynthetic capacity maybe for the low symbiosis cost; we based our hypothesis on the statement that blue light exerts an inhibitory effect on microbes' growth and development. However, it cannot be excluded that the lower carbon allocation to root, observed in RB plants, might indicate also an efficient nutrient and water transport via fungi (Kothari et al. 1990). In this case, the blue light might have promoted a higher nitrate reductase activity improving the nitrate assimilation in these plants, as found by other authors (Agarwal et al. 2018).
Conclusions: Light quality influences the phenotypic plasticity of spinach plants, inducing changes in morphology and physiology. The green wavelength promotes the plant carbon gain enhancing the photosynthetic rates and reducing the limitation to $\mathrm{CO}_{2}$ diffusion. The exposure to pure red increases the photosynthesis promoting the light harvesting and improving the $\mathrm{CO}_{2}$ diffusion to carboxylation sites that reduce significantly the photorespiration. Light modulation also affects the secondary metabolites synthesis and the antioxidant capacity. The interaction between light quality and microorganism-based biofertilizer alters the spinach phenotypic plasticity affecting the plant responses to microbes. In particular, the growth under pure red light promotes the root colonisation by microorganisms raising the costs of symbiosis. Under this condition, the interaction of plant-microorganisms becomes unfavourable.

\section{References}

Agarwal A., Dutta Gupta S., Barman M., Mitra A.: Photosynthetic apparatus plays a central role in photosensitive physiological acclimations affecting spinach (Spinacia oleracea L.) growth in response to blue and red photon flux ratios. - Environ. Exp. Bot. 156: 170-182, 2018.

Ahemad M., Kibret M.: Mechanisms and applications of plant growth promoting rhizobacteria: Current perspective. J. King Saud. Univ. Sci. 26: 1-20, 2014.

Alsanius B.W., Karlsson M., Rosberg A.K. et al.: Light and microbial lifestyle: the impact of light quality on plantmicrobe interactions in horticultural production systems. A review. - Horticulturae 5: 41, 2019.

Amitrano C., Vitale E., De Micco V., Arena C.: Light fertilization affects growth and photosynthesis in mung bean (Vigna radiata) plants. - J. Environ. Account. Manage. 6: 295-304, 2018.

Arena C., Tsonev T., Doneva D. et al.: The effect of light quality on growth, photosynthesis, leaf anatomy and volatile isoprenoids of a monoterpene-emitting herbaceous species (Solanum lycopersicum L.) and an isoprene-emitting tree (Platanus orientalis L.). - Environ. Exp. Bot. 130: 122-132, 2016.

Arena C., Vitale E., Hay Mele B.et al:: Suitability of Solanum lycopesicum L. 'Microtom' for growth in Bioregenerative Life Support Systems: exploring the effect of high-LET ionising radiation on photosynthesis, leaf structure and fruit trait. - Plant Biol. 21: 615-626, 2019.

Çakmakçı R., Erat M., Erdoğan Ü., Dönmez M.F.: The influence of plant growth-promoting rhizobacteria on growth and enzyme activities in wheat and spinach plants. - J. Plant Nutr. Soil Sc. 170: 288-295, 2007.

Canamero R.C., Bakrim N., Bouly J.P. et al:: Cryptochrome photoreceptors cry1 and cry2 antagonistically regulate primary root elongation in Arabidopsis thaliana. - Planta 224: 995-1003, 2006.

Chang S.X., Li C.X., Yao X.Y. et al.: Morphological, photosynthetic, and physiological responses of rapeseed leaf to different combinations of red and blue lights at the rosette stage. - Front. Plant Sci. 7: 1144, 2016.

Clark M., Tilman D.: Comparative analysis of environmental impacts of agricultural production systems, agricultural input 
efficiency, and food choice. - Environ. Res. Lett. 12: 064016 , 2017.

Compant S., Duffy B., Nowak J. et al.: Use of plant growthpromoting bacteria for biocontrol of plant diseases: Principles, mechanisms of action, and future prospects. - Appl. Environ. Microb. 71: 4951-4959, 2005.

Cornelissen J.H.C., Lavorel S., Garnier E.et al.: A handbook of protocols for standardised and easy measurement of plant functional traits worldwide. - Aust. J. Bot. 51: 335-380, 2003.

Cruz A.F.: Effect of light-emitting diodes on arbuscular mycorrhizal fungi associated with bahiagrass (Paspalum notatum Flugge) and millet [(Pennisetum glaucum (L.) R. Br]. - Bioagro 28: 163-170, 2016.

De Lucca A., Carter-Wientjes C., Williams K., Bhatnagar D.: Blue light $(470 \mathrm{~nm})$ effectively inhibits bacterial and fungal growth. - Lett. Appl. Microbiol. 55: 460-466, 2012.

Doornbos R.F., van Loon L.C., Bakker P.A.H.M.: Impact of root exudates and plant defence signalling on bacterial communities in the rhizosphere. A review. - Agron. Sustain. Dev. 32: 227-243, 2012.

Folta K.M.: Green light effects on plant growth development. In: Wada M., Shimazaki K., Iino M. (ed.): Light Sensing in Plants. Pp. 370. Springer, Tokyo 2005.

Genty B., Briantais J.M., Baker N.R.: The relationship between the quantum yield of photosynthetic electron transport and quenching of chlorophyll fluorescence. - BBA-Gen. Subjects 990: 87-92, 1989.

George B., Kaur C., Khurdiya D.S., Kapoor H.C.: Antioxidants in tomato (Lycopersicum esculentum) as a function of genotype. - Food Chem. 84: 45-51, 2004.

Hedge J.E., Hofreiter B.T.: Carbohydrate chemistry. - In: Whistler R.L., Be Miller J.N. (ed.): Methods in Carbohydrate Chemistry. Vol. 17. Academic Press, New York 1962.

Heo J., Lee C., Chakrabarty D., Paek K.: Growth responses of marigold and salvia bedding plants as affected by monochromic or mixture radiation provided by a LightEmitting Diode (LED). - Plant Growth Regul. 38: 225-230, 2002.

Hernández R., Kubota C.: Physiological responses of cucumber seedlings under different blue and red photon flux ratios using LEDs. - Environ. Exp. Bot. 121: 66-74, 2016.

Hristozkova M., Geneva M., Stancheva I., Velikova V.: LED spectral composition effects on mycorrhizal symbiosis formation with tomato plants. - Appl. Soil Ecol. 120: 189196, 2017.

Izzo L.G., Arena C., De Micco V. et al.: Light quality shapes morpho-functional traits and pigment content of green and red leaf cultivars of Atriplex hortensis. - Sci. Hortic.-Amsterdam 246: 942-950, 2019.

Johkan M., Shoji K., Goto F. et al.: Effect of green light wavelength and intensity on photomorphogenesis and photosynthesis in Lactuca sativa. - Environ. Exp. Bot. 75: 128-133, 2012.

Kaschuk G., Kuyper T.W., Leffelaar P.A. et al:: Are the rates of photosynthesis stimulated by the carbon sink strength of rhizobial and arbuscular mycorrhizal symbioses? - Soil Biol. Biochem. 41: 1233-1244, 2009.

Khalid M., Hassani D., Bilal M. et al.: Influence of bio-fertilizer containing beneficial fungi and rhizospheric bacteria on health promoting compounds and antioxidant activity of Spinacia oleracea L. - Bot. Stud. 58: 35, 2017.

Kim H.H., Goins G., Wheeler R., Sager J.C.: Green-light supplementation for enhanced lettuce growth under red and blue LEDs. - HortScience 39: 1616-1622, 2004.

Kothari S., Marshner H., George E.: Effect of VA mycorrhizal fungi and rhizosphere microorganisms on root and shoot morphology, growth and water relations in maize. - New
Phytol. 116: 303-311, 1990.

Krall J.P., Edwards G.E.: Relationship between photosystem II activity and $\mathrm{CO}_{2}$ fixation in leaves. - Physiol. Plantarum 86: 180-187, 1992.

Kramer D.M., Johnson G., Kiirats O., Edwards G.E.: New fluorescence parameters for the determination of $\mathrm{Q}_{\mathrm{A}}$ redox state and excitation energy fluxes. - Photosynth Res. 79: 209218, 2004.

Laisk A., Oja V.: Dynamics of Leaf Photosynthesis. RapidResponse Measurements and their Interpretations. Pp. 160. CSIRO Publishing, Melbourne 1998.

Landi M., Tattini M., Gould K.S.: Multiple functional roles of anthocyanins in plant-environment interactions. - Environ. Exp. Bot. 119: 4-17, 2015.

Lichtenthaler H.K.: Chlorophylls and carotenoids: Pigments of photosynthetic biomembranes. - Method. Enzymol. 148: 350382, 1987.

Lobiuc A., Vasilache V., Pintilie O. et al.: Blue and red LED illumination improves growth and bioactive compounds contents in acyanic and cyanic Ocimum basilicum L. microgreens. - Molecules 22: 2111, 2017.

Loreto F., Harley P.C., Di Marco G., Sharkey T.D.: Estimation of mesophyll conductance to $\mathrm{CO}_{2}$ flux by three different methods. - Plant Physiol. 98: 1437-1443, 1992.

Loreto F., Tsonev T., Centritto M.: The impact of blue light on leaf mesophyll conductance. - J. Exp. Bot. 60: 2283-2290, 2009.

Mancinelli A.L., Huang Yang C.-P., Lindquist P. et al.: Photocontrol of anthocyanin synthesis. III. The action of streptomycin on the synthesis of chlorophyll and anthocyanin. - Plant Physiol. 55: 251-257, 1975.

Matsuda R., Ohashi-Kaneko K., Fujiwara K., Kurata K.: Analysis of the relationship between blue-light photon flux density and the photosynthetic properties of spinach (Spinacia oleracea L.) leaves with regard to the acclimation of photosynthesis to growth irradiance. - Soil Sci. Plant Nutr. 53: 459-465, 2007.

Matsuda R., Ohashi-Kaneko K., Fujiwara K., Kurata K.: Effects of blue light deficiency on acclimation of light energy partitioning in PSII and $\mathrm{CO}_{2}$ assimilation capacity to high irradiance in spinach leaves. - Plant Cell Physiol. 49: 664670, 2008.

Mhlongo M.I., Piater L.A., Madala N.E. et al.: The chemistry of plant-microbe interactions in the rhizosphere and the potential for metabolomics to reveal signalling related to defence priming and induced systemic resistance. - Front. Plant Sci. 9: 112, 2018.

Motta C.M., Simoniello P., Arena C. et al.: Effects of four food dyes on development of three model species, Cucumis sativus, Artemia salina and Danio rerio: Assessment of potential risk for the environment. - Environ. Pollut. 253: 1126-1135, 2019.

Nascente A.S., de Filippi M.C.C., Lanna A.C. et al.: Effects of beneficial microorganisms on lowland rice development. Environ. Sci. Pollut. R. 24: 25233-25242, 2017.

Niinemets Ü., Díaz-Espejo A., Flexas J. et al.: Role of mesophyll diffusion conductance in constraining potential photosynthetic productivity in the field. - J. Exp. Bot. 60: 2249-2270, 2009.

Ohashi-Kaneko K., Takase M., Kon N. et al.: Effect of light quality on growth and vegetable quality in leaf lettuce, spinach and komatsuna. - Environ. Control Biol. 45: 189-198, 2007.

Pallozzi E., Tsonev T., Marino G. et al.: Isoprenoid emissions: photosynthesis and mesophyll diffusion conductances in response to blue light. - Environ. Exp. Bot. 95: 50-58, 2013.

Paradiso R., Arena C., Rouphael Y. et al.: Growth, photosynthetic activity and tuber quality of two potato cultivars in controlled environment as affected by light source. - Plant Biosyst. 153: 
725-735, 2019.

Purschwitz J., Müller S., Kastner C., Fischer R.: Seeing the rainbow: light sensing in fungi. - Curr. Opin. Microbiol. 9: 566-571, 2007.

Samuolienè G., Brazaitytė A., Viršilè A. et al.: Red light-dose or wavelength-dependent photoresponse of antioxidants in herb microgreens. - PLoS ONE 11: e0163405, 2016.

Schuerger A.C., Brown C.S., Stryjewski E.C.: Anatomical features of pepper plants (Capsicum annuum L.) grown under red light-emitting diodes supplemented with blue or far-red light. - Ann. Bot.-London 79: 273-282, 1997.

Singh D., Basu C., Meinhardt-Wollweber M., Roth B.: LEDs for energy efficient greenhouse lighting. - Renew. Sust. Energ. Rev. 49: 139-147, 2015.

Smith H.L., McAusland L., Murchie E.H.: Don't ignore the green light: exploring diverse roles in plant processes. - J. Exp. Bot. 68: 2099-2110, 2017.

Spaepen S., Vanderleyden J.: Auxin and plant-microbe interactions. - Cold Spring Harb. Perspect. Biol. 3: a001438, 2011.

Steyn W.J., Wand S.J.E, Holcroft D.M., Jacobs G.: Anthocyanins in vegetative tissues: a proposed unified function in photoprotection. - New Phytol. 155: 349-361, 2002.

Terashima I., Fujita T., Inoue T. et al:: Green light drives leaf photosynthesis more efficiently than red light in strong white light: revisiting the enigmatic question of why leaves are green. - Plant Cell Physiol. 50: 684-697, 2009.

Tomás M., Flexas J., Copolovici L. et al:: Importance of leaf anatomy in determining mesophyll diffusion conductance to $\mathrm{CO}_{2}$ across species: quantitative limitations and scaling up by models. - J. Exp. Bot. 64: 2269-2281, 2013.

Urbonaviciute A., Pinho P., Samuoliene G. et al.: Effect of shortwavelength light on lettuce growth and nutritional quality. Sodininkyste Ir Darzininkyste 26: 157-165, 2007.

Victório C.P., Leal-Costa M.V., Tavares E.S. et al.: Light spectral affect the morphoanatomical and chemicals features of clonal
Phyllantus tenellus Roxb. grown in vitro. - J. Med. Plants Res. 9: 111-121, 2015.

Vierheilig H., Coughlan A.P., Wyss U., Piché Y.: Ink and vinegar, a simple staining technique for arbuscular-mycorrhizal fungi. - Appl. Environ. Microb. 64: 5004-5007, 1998.

Vierheilig H., Piché Y.: A modified procedure for staining arbuscular mycorrhizal fungi in roots. - J. Plant. Nutr. Soil Sc. 161: 601-602, 1998.

von Caemmerer S., Farquhar G.D.: Some relationships between the biochemistry of photosynthesis and the gas exchange of leaves. - Planta 153: 376-387, 1981.

Walker A.P., Beckerman A.P., Gu L. et al.: The relationship of leaf photosynthetic traits $-V_{\text {cmax }}$ and $J_{\max }$ - to leaf nitrogen, leaf phosphorus, and specific leaf area: meta-analysis and modeling study. - Ecol. Evol. 4: 3218-3235, 2014.

Wang J., Lu W., Tong Y., Yang Q.: Leaf morphology, photosynthetic performance, chlorophyll fluorescence, stomatal development of lettuce (Lactuca sativa L.) exposed to different ratios of red light to blue light. - Front. Plant Sci. 7: 250, 2016.

Ye S., Shao Q., Xu M. et al.: Effects of light quality on morphology, enzyme activities, and bioactive compound contents in Anoectochilus roxburghii. - Front. Plant Sci. 8: 857, 2017.

Yorio N.C., Goins G.D., Kagie H.R. et al.: Improving spinach, radish, and lettuce growth under red light emitting diodes (LEDs) with blue light supplementation. - HortScience 36: 380-383, 2001.

Zheng L., Van Labeke M.-C.: Long-term effects of red- and bluelight emitting diodes on leaf anatomy and photosynthetic efficiency of three ornamental pot plants. - Front. Plant Sci. 8: 917, 2017.

Zuccarini P., Savé R.: Three species of arbuscular mycorrhizal fungi confer different levels of resistance to water stress in Spinacia oleracea L. - Plant Biosyst. 150: 851-854, 2016.

(C) The authors. This is an open access article distributed under the terms of the Creative Commons BY-NC-ND Licence. 